M.I. Martín, F.A. López, F.J. Alguacil, M. Romero. Development of crystalline phases in sintered glassceramics from residual E-glass fibres. Ceramics International, 40 (2014) 2769-2776

\title{
Development of crystalline phases in sintered glass-ceramics from residual E-glass fibres
}

\author{
M.I. Martín, F.A. López, F.J. Alguacil and M. Romero
}

\begin{abstract}
${ }^{a}$ Group of Glass and Ceramic Materials, Department of Construction, Eduardo Torroja Institute for Construction Science (IETcc), CSIC. Serrano Galvache, 4, 28033 Madrid, Spain

${ }^{\mathrm{b}}$ Recycling Materials Laboratory, National Center for Metallurgical Research (CENIM), CSIC. Avda. Gregorio del Amo 8, 28040 Madrid, Spain
\end{abstract}

*Corresponding author; E-mail address: mromero@ietcc.csic.es

\begin{abstract}
The crystalline phase evolution during firing of glass-ceramic materials from residual E-glass fibres was investigated as a function of temperature and time. The thermal stability and crystallisation mechanism were studied by differential scanning calorimetry (DSC). The mineralogical and microstructural characterisation of the sintered glass-ceramics was carried out by X-ray diffraction (XRD) and field emission scanning electron microscopy (FESEM), respectively. The crystallisation behaviour was depicted by the TTT (Time-TemperatureTransformation) curve. The activation energies for crystallisation were calculated by the Friedman differential isoconversional method. The results show that devitrification of the glass leads to a series of glass-ceramic materials composed of wollastonite and plagioclase s.s. Their microstructure is composed of a dense network of crystals, which is responsible for the high mechanical properties exhibited by these materials.
\end{abstract}

Keywords: A. Sintering; B. Microstructure-final; D. Glass-ceramics

\section{Introduction}

Glass-ceramics are ceramic materials produced from parent glasses by sequential thermal processes involving controlled crystallisation, which consists of the growth of one or more crystalline phases within the vitreous mass [1]. The earliest reported glass-ceramics were produced by a conventional glass route and subsequently crystallised, usually by heat treatment 
M.I. Martín, F.A. López, F.J. Alguacil, M. Romero. Development of crystalline phases in sintered glassceramics from residual E-glass fibres. Ceramics International, 40 (2014) 2769-2776

doi: 10.1016/j.ceramint.2013.10.040

in two stages, to produce nucleation and subsequent crystal growth. In recent years, the sintering method has proven to be a technically viable route for the manufacture of glass-ceramics. This process usually involves milling a glass frit into fine particles, which are then shaped by conventional forming techniques and subsequently heat treated to provide sintering and crystallisation of the glass particles. A sintering process is normally used when the parent glass exhibits a strong tendency for surface crystallisation or when complex shapes are required [2]. Because the most important glass-forming systems are based on silicate compositions, the key crystalline phases of glass-ceramics are principally silicates [3].

Fibre-reinforced plastic (FRP) is a composite material made of a polymer matrix (usually an epoxy, vinylester or polyester thermosetting plastic) reinforced with fibres (usually glass, carbon, basalt or aramid). The global production of FRPs increases every year, and output is expected to reach 10.3 Mt in 2015. Approximately 90\% of FRPs correspond to thermostable composites containing glass fibres as a strengthening constituent (Fibreglass Reinforced Plastics (FGRPs)). FGRPs play important roles in high-performance applications in civil, mechanical and biomechanical engineering, as well as in automobile manufacturing and the aeronautical industry. The sustainable elimination of FGRP wastes remains challenging. Their recycling is unviable in economic terms because the recycled fibres possess lower mechanical properties than they did originally; thus, they cannot be employed in the manufacture of structural materials. Therefore, the majority of waste fibreglass reinforced composites are stored in landfills or buried. This waste causes serious environmental problems due to the nonbiodegradable and bulky nature of these types of waste. The applied European legislation to these wastes [4-6] limits the amount of that may be discarded in landfills. Additionally, the United Kingdom and Germany have implemented a total ban for the dumping of these waste materials.

A number of technologies have been proposed for recycling thermoset composites: mechanical comminution-based processes [7]; thermal processes such as combustion, pyrolysis, thermolysis, etc. [8-10]; and composite depolymerisation based on chemical processes such as hydrolysis, glycolysis and solvolysis [11]. However, none of these techniques achieves more than partial recovery of the glass fibres.

In recent studies [12,13], we demonstrated the feasibility of obtaining wollastonite-plagioclase glass-ceramics through sinter-crystallisation of a parent glass made from glass fibres pyrolytically recovered from FGRP wastes. The developed glass-ceramics possess technological properties very suitable for both indoor and outdoor architectural applications. Their most 
M.I. Martín, F.A. López, F.J. Alguacil, M. Romero. Development of crystalline phases in sintered glassceramics from residual E-glass fibres. Ceramics International, 40 (2014) 2769-2776

doi: 10.1016/j.ceramint.2013.10.040

advantageous properties are high flexural strength (100-120 MPa), high resistance to weathering and a zero water absorption rate.

It is known that the most important factors that affect the technical properties of glass-ceramics are the nature of the devitrified crystalline phases, their shape, size and spatial arrangement. Hence, this work analyses the evolution of the crystalline phases and microstructures during the crystallisation process of a glass derived from FGRP wastes.

To a first valuation of the technological properties, the glass-ceramic crystallised for 20 in 1030 ${ }^{\circ} \mathrm{C}$ were tested to determine the water absorption, open porosity and bulk density (ISO 105453:1997 [14] and bending strength (EN 843-1:2006 [15] in an electronic universal tester (Servosis model ME-402/01) on ten specimens by a three point loading test with a span of 32 $\mathrm{mm}$ and a crosshead speed of $1 \mathrm{~mm} / \mathrm{min}$.

\section{Materials and methods}

The material used in the present work was a glass (hereafter referred to as PGF glass), pyrolytically generated from glass fibres recovered from waste composite materials. This composite was a fibreglass-reinforced polyester (FGRP) produced by POLIFIBRA, S.A. (Guadalajara, Spain), composed of unsaturated polyester resin (32.8 wt\% orthophthalic polymer resin, $1.2 \mathrm{wt} \%$ styrene monomer, $1.2 \mathrm{wt} \% \mathrm{Zn}$ stearate and $0.3 \mathrm{wt} \%$ organic catalyst) and 64.5 wt $\%$ E-glass fibre. The FGRP was heated at $550^{\circ} \mathrm{C}$ for $3 \mathrm{~h}$ in a pyrolysis reactor $[12,13]$ where complex organic compounds (oils), non-condensable gases and glass fibre were obtained as reaction products.

Prior to use, the recovered fibres (97 wt $\%$ E-glass fibre and $3 \mathrm{wt} \%$ residual organic matter) were milled and then sieved to a particle size $<250 \mu \mathrm{m}$. Na2O (as $\mathrm{Na}_{2} \mathrm{CO}_{3}$ of A.R. quality) was incorporated at $5 \mathrm{wt} \%$ into the PGF glass formulation to facilitate melting. The $95 \mathrm{wt} \%$ recovered glass fibre and $5 \mathrm{wt} \% \mathrm{Na}_{2} \mathrm{O}$ batches were mixed for $30 \mathrm{~min}$ in a blender (TURBULA) to obtain homogeneity. Each batch was transferred to an aluminosilicate crucible and heated in an electric furnace to $1450^{\circ} \mathrm{C}$ at a rate of $10^{\circ} \mathrm{C} / \mathrm{min}$. After a holding time of $120 \mathrm{~min}$ at the melting temperature, the melt was quenched by pouring into water, producing a glass frit (PGF glass frit). 
M.I. Martín, F.A. López, F.J. Alguacil, M. Romero. Development of crystalline phases in sintered glassceramics from residual E-glass fibres. Ceramics International, 40 (2014) 2769-2776

doi: 10.1016/j.ceramint.2013.10.040

The chemical composition of the recovered glass fibre and the synthesised PFG glass was determined by X-ray fluorescence (XRF) (Brucker model S8 Tiger with a tungsten tube, LiF crystal analyser and generator of $4 \mathrm{~kW}$ ). The boron determination (as $\mathrm{B}_{2} \mathrm{O}_{3}$ ) was made separately by inductively coupled plasma optical emission spectrometry (ICP-OES) (Varian 725-ES ICP Optical Emission Spectrometer).

The PGF glass frits were was ground using a BIOMETAL RETSCH PM 100 ball mill at 400 rpm and sieved to a particle size of 80-100 $\mu \mathrm{m}$.

The activation energy for crystallisation was calculated by differential scanning calorimetry (DSC) on powder samples (80-100 $\mu \mathrm{m}$ particle size). DSC experiments were performed on a SETARAM Model Labsys. DSC analyses were carried out at five different heating rates (10, $20,30,40$ and $50^{\circ} \mathrm{C} / \mathrm{min}$ ) between $25^{\circ} \mathrm{C}$ and $1450^{\circ} \mathrm{C}$. The DSC scans were conducted under a flow of air in platinum crucibles, and calcined $\mathrm{Al} 2 \mathrm{O} 3$ was used as a reference material. The DSC curves were normalised with respect to the sample weight.

The activation energy for the crystallisation process was calculated using the Friedman method (FR) [16].

For solid-state reactions, it is generally assumed that the rates of conversion are proportional to the concentration of the reacted material. The rate of conversion can be expressed by the following basic rate equation (Eq. 1):

$$
\frac{d \alpha}{d t}=\beta \frac{d \alpha}{d T}=k(T) \cdot f(\alpha)
$$

where $\alpha$ is the degree of conversion of the reaction, $f(\alpha)$ and $k(T)$ are functions of conversion and temperature, respectively and $\beta$ the reaction rate. In the DSC experiments, Eq. (1) can be expressed as follows:

$$
\frac{d \alpha}{d t}=\frac{d H}{d t} \cdot \frac{1}{\Delta H \text { total }}
$$

where $\mathrm{dH} / \mathrm{dt}$ is the heat flow above the baseline, and is the peak area of the reaction expressed in $\mathrm{mJ}$.

By combining Eqs. (1) and (2), the rate of conversion can be written in the following form: 
$\frac{d \alpha}{d t}=\frac{d H}{d t} \cdot \frac{1}{\Delta H \text { total }}=k(T) \cdot f(\alpha)$

where $\mathrm{k}(\mathrm{T})$ is the temperature dependence of the rate of heat flow, often modelled successfully by the Arrhenius equation:

$k(T)=A \exp \left(-\frac{E}{R T}\right)$

where $\mathrm{E}$ is the activation energy, $\mathrm{A}$ is the pre-exponential factor, and $\mathrm{R}$ is the gas constant.

By combining Eqs. (3) and (4), the reaction rate can be written as follows:

$\frac{d \alpha}{d t}=A \exp \left(-\frac{E}{R T}\right) \cdot f(\alpha)$

Friedman analysis (FR), based on the Arrhenius equation, applies the logarithm of the conversion rate $d \alpha / d t$ as a function of the reciprocal temperature at different degrees of the conversion $\alpha$, according to Eq. (6):

$\left.\ln \frac{d \alpha}{d t}\right|_{\alpha i}=\ln \left(A_{i} f\left(\alpha_{i, j}\right)\right)-\frac{E_{a i}}{R \cdot T_{i, j}}$

where $i$ is the index of conversion, $j$ is the index of the curve, Eai is the apparent activation energy at $\alpha \mathrm{i}$, and $\mathrm{f}(\alpha \mathrm{i}, \mathrm{j})$ is the function dependent on the reaction model that is assumed to be constant for a given reaction progress $\alpha \mathrm{i}, \mathrm{j}$ for all curves $\mathrm{j}$. As $\mathrm{f}(\alpha)$ is constant at each conversion degree $\alpha$ i, the dependence of the logarithm of the reaction rate to $1 / \mathrm{T}$ is linear with the slope of $\mathrm{E} \alpha / \mathrm{R}$ and intercept $\mathrm{A}$.

The analysis according to ASTM E698 [17] is based on the assumption that the maximum (for example maximum of the DSC peaks) of a single step reaction is reached at the same conversion degree independent of the heating rate. Although this assumption is only partly right, the resulting errors are small. In this method, the logarithm of the heating rate is plotted over the reciprocal temperature of the maximum. The slope of the yielded straight line is proportional to the activation energy, according to Eq. (7): 
$\ln \left(\frac{\beta}{T}\right)=\ln A+\ln (1-\alpha)+\frac{E}{R} \frac{a}{T}$

The data were also analysed using the Kissinger method [18]:

$\ln \left(\beta / \mathrm{Tp}^{2}\right)=-\mathrm{E} / \mathrm{R} \cdot \mathrm{Tp}+\mathrm{constant}$

where Tp is the maximum of the DSC crystallisation peak, $\beta$ is the heating rate, $\mathrm{E}$ is the activation energy and $\mathrm{R}$ is the ideal gas constant.

In a previous paper [12], it was noted that the devitrification process of PFG glass went through a surface crystallisation mechanism. Thus, the most effective method for manufacturing glassceramic materials from PGF glass frit is by a sinter-crystallisation process, which involves the sintering and subsequent crystallisation of powdered glass. Therefore, the crystallisation study was performed on a PGF glass sample ground and sieved to a particle size of 80-100 $\mu \mathrm{m}$.

The development of the crystalline phases after thermal treatment of the PGF glass was studied on compacted glass samples. Powdered glass $(80-100 \mu \mathrm{m}$ particle size) was moistened by spraying with distilled water $(2 \mathrm{wt} \%)$. Glass compacts $(10 \times 10 \times 5 \mathrm{~mm})$ were shaped by uniaxial pressing (Nannetti S hydraulic press) at $40 \mathrm{MPa}$ in a steel die. To evaluate the effect of temperature on the development of the crystalline phases of end glass-ceramics, the compacts were treated at different temperatures $\left(800-1100^{\circ} \mathrm{C}\right)$ for several different times (2-60 min). After treatment, the samples were taken out of the oven and air cooled to room temperature.

The evaluation of the amorphous nature of the synthesised PFG glass and the mineralogical study of the crystalline phases devitrified after thermal treatment were performed by X-ray diffraction (XRD) (Philips model X 'PERT MPD) with Ni-filtered $\mathrm{Cu} \mathrm{K} \alpha$ radiation operating at $30 \mathrm{~mA}$ and $50 \mathrm{kV}$. Data were recorded in the $3-75^{\circ} 2 \theta$ range (step size $0.019732^{\circ}$ and $0.5 \mathrm{~s}$ counting time for each step).

The microstructural analysis of the glass-ceramics was performed by field emission scanning electron microscopy (FESEM) (HITACHI model S-4800) operating at $20 \mathrm{kV}$. A semiquantitative analysis of the different phases was obtained by energy dispersive X-ray spectroscopy (EDS) using an RX BRUKER detector. SEM specimens were prepared from freshly fractured glass-ceramic surfaces. To enhance the SEM observations, all samples were Au-Pd coated using a Balzers SCD 050 sputter. 
M.I. Martín, F.A. López, F.J. Alguacil, M. Romero. Development of crystalline phases in sintered glassceramics from residual E-glass fibres. Ceramics International, 40 (2014) 2769-2776

\section{Results and discussion}

Table 1 shows the chemical composition of the PGF glass. It consists mainly of $\mathrm{SiO}_{2}, \mathrm{CaO}$, $\mathrm{Al}_{2} \mathrm{O}_{3}, \mathrm{~B}_{2} \mathrm{O}_{3}$ and $\mathrm{Na}_{2} \mathrm{O}$ in percentages close to those of E-glass fibre composition, which is the constituent of the original FGRP wastes. The main difference is the concentration of $\mathrm{Na}_{2} \mathrm{O}$, which is slightly higher in the PGF glass because it was formulated with the incorporation of 5 wt $\% \mathrm{Na}_{2} \mathrm{O}$ as a fluxing agent. Fig. 1 illustrates the appearance (a) and the X-ray diffraction pattern (b) of the PGF glass. The amorphous halo characteristic of disordered structure in glass is evident.

Table 1. Chemical composition (wt.\%) of the PGF glass.

\begin{tabular}{lc}
\hline Oxide & PFG glass \\
\hline $\mathrm{SiO}_{2}$ & 52.86 \\
$\mathrm{CaO}$ & 20.36 \\
$\mathrm{Al}_{2} \mathrm{O}_{3}$ & 13.95 \\
$\mathrm{~B}_{2} \mathrm{O}_{3}$ & 6.03 \\
$\mathrm{Na}_{2} \mathrm{O}$ & 5.82 \\
$\mathrm{MgO}$ & 0.24 \\
$\mathrm{~K}_{2} \mathrm{O}$ & 0.24 \\
$\mathrm{Fe}_{2} \mathrm{O}_{3}$ & 0.25 \\
$\mathrm{TiO}_{2}$ & 0.20 \\
$\mathrm{SrO}_{\mathrm{ZrO}}$ & 0.02 \\
\hline
\end{tabular}

Fig. 2 depicts the DSC curves for the PGF glass recorded at different heating rates from 25 to $1450^{\circ} \mathrm{C}$. The first endothermic jump in the baseline at $\sim 693^{\circ} \mathrm{C}$ corresponds to the glass transition temperature (Tg). After that, the two exothermic effects centred at $\sim 819-860^{\circ} \mathrm{C}$ and $963-1099^{\circ} \mathrm{C}$ denote that this glass is not thermally stable and that subsequent thermal treatment will lead to a crystallisation process with the consequent formation of glass-ceramic materials. Finally, an endothermic reaction starting at $\sim 1150^{\circ} \mathrm{C}$ indicates the formation of liquid phases.

Fig. 3 shows the plot of $\ln (\beta / \mathrm{Tp} 2)$ versus $1 / \mathrm{Tp}$. A linear relationship was obtained for both crystallisation peaks, in accordance with the Kissinger equation (Eq. 8). The values of the activation energy (E) calculated from the slopes of these plots are $480.0 \mathrm{~kJ} / \mathrm{mol}$ and 282.0 $\mathrm{kJ} / \mathrm{mol}$ for the first and second crystallisation peaks, respectively. 
M.I. Martín, F.A. López, F.J. Alguacil, M. Romero. Development of crystalline phases in sintered glassceramics from residual E-glass fibres. Ceramics International, 40 (2014) 2769-2776
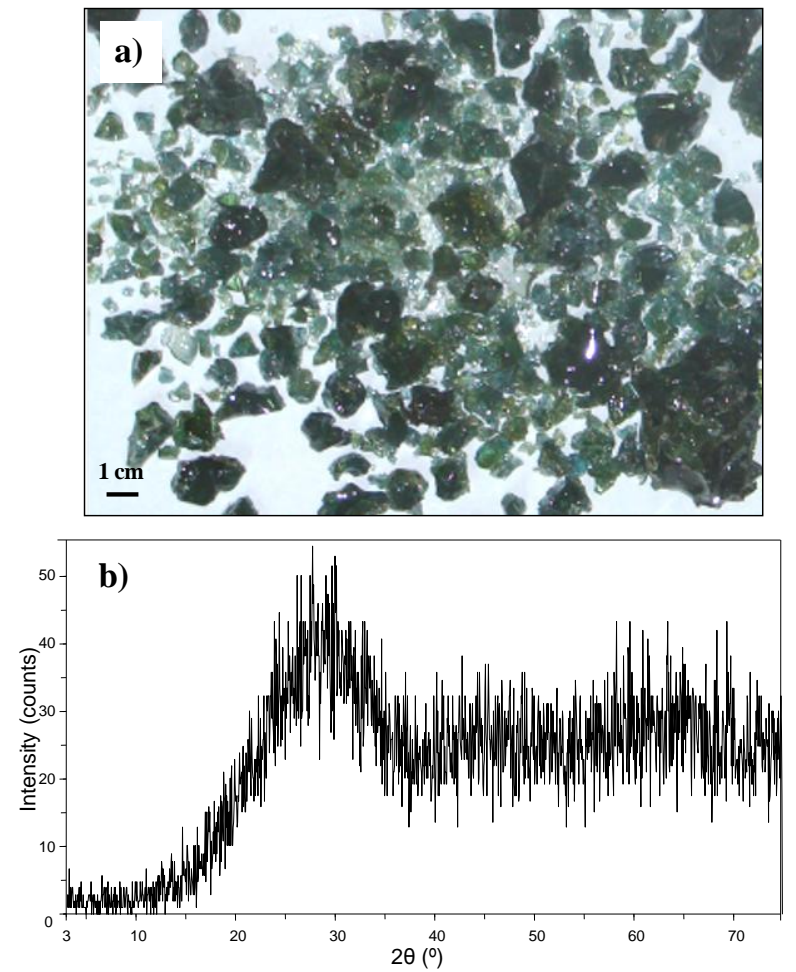

Figure 1. a) Appearance of the PGF glass; b) X-ray diffraction patterns for the PFG glass.

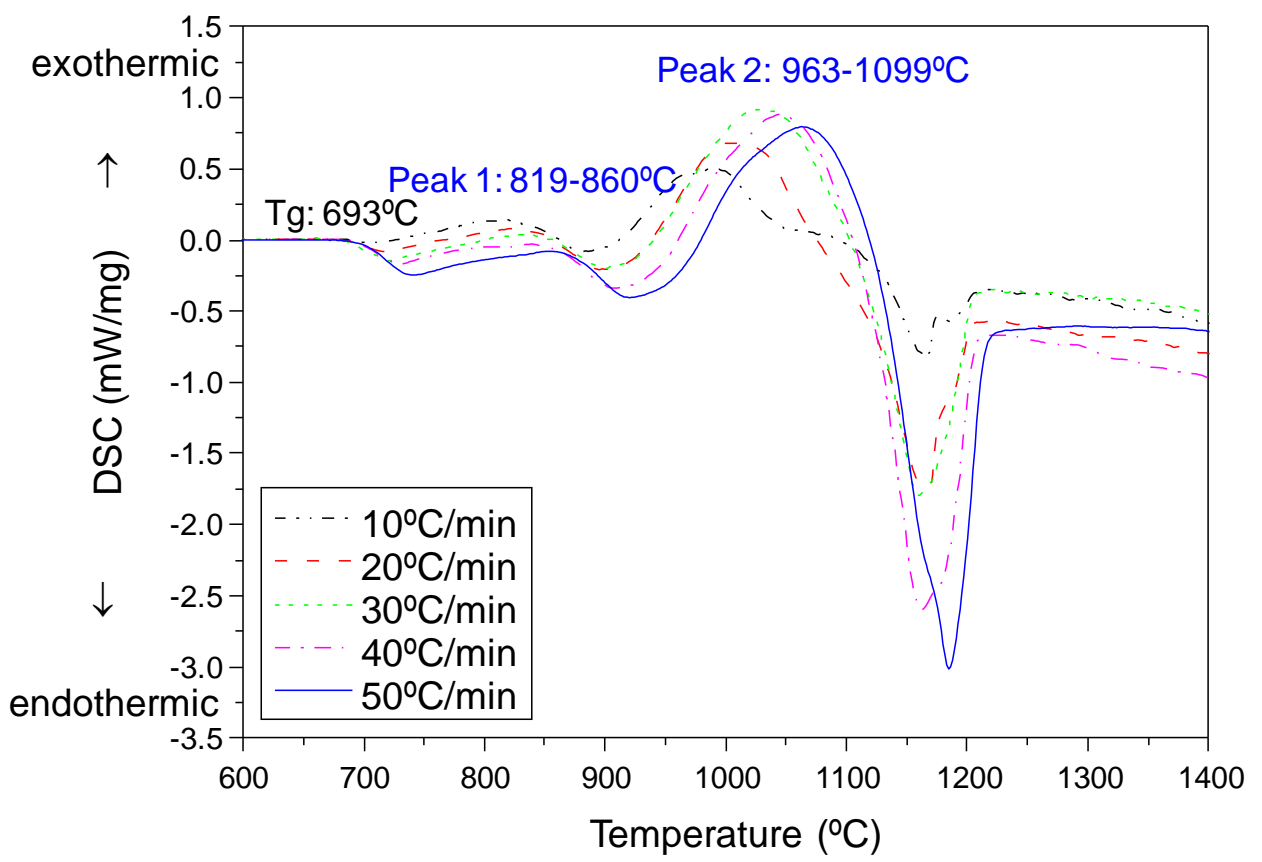

Figure 2. DSC curves for the PGF glass at different heating rates. 
M.I. Martín, F.A. López, F.J. Alguacil, M. Romero. Development of crystalline phases in sintered glassceramics from residual E-glass fibres. Ceramics International, 40 (2014) 2769-2776

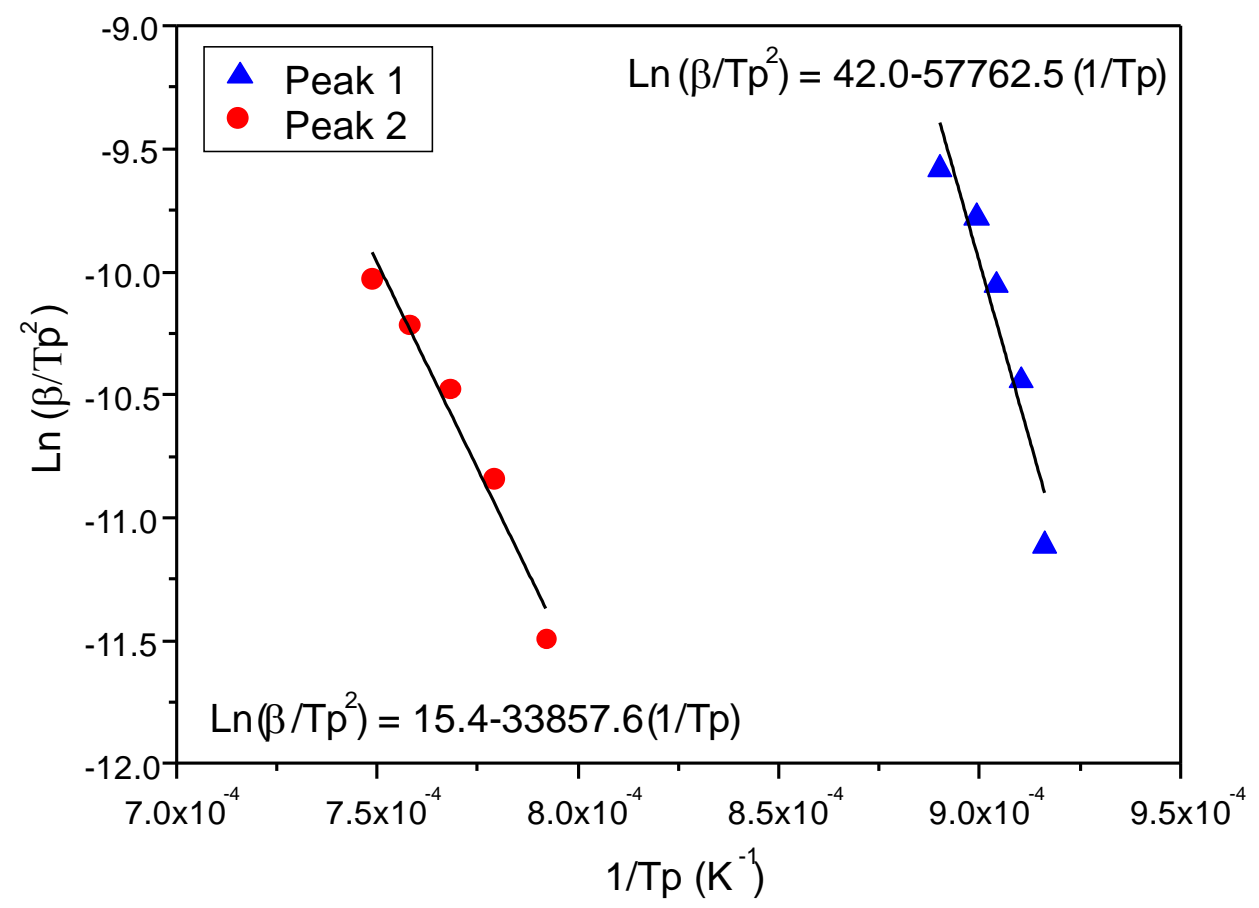

Figure 3. Determination of the activation energy for crystallisation by the Kissinger equation (Peak 1 and Peak 2 correspond to the exotherms at 860 and $1099^{\circ} \mathrm{C}$ respectively).

Table 2 shows the values of the apparent activation energies of the crystallisation peaks calculated by Friedman analysis (Eq. 6), ASTM E698 (Eq. 7) and Kissinger method (Eq. 8). For the first peak, the apparent activation energy is $419.3 \pm 41.1 \mathrm{~kJ} / \mathrm{mol}, 390.8 \mathrm{~kJ} / \mathrm{mol}$ and 480.0 $\mathrm{kJ} / \mathrm{mol}$ for Friedman, ASTM and Kissinger respectively and is $139.8 \pm 7.0 \mathrm{~kJ} / \mathrm{mol}, 135.5 \mathrm{~kJ} / \mathrm{mol}$ and $282.0 \mathrm{~kJ} / \mathrm{mol}$ for Friedman, ASTM and Kissinger respectively for the second peak. The activation energies values obtained by the Friedman and ASTM methods were similar and slightly higher the ones obtained with the Kissinger method.

Table 2. Activation energies of crystallisation reactions calculated by the differential isoconversional method of Friedman, ASTM and Kissinger methods.

\begin{tabular}{ccc}
\hline Method & $\mathbf{E}_{\text {peak 1 }}(\mathbf{k J} / \mathbf{m o l})$ & $\mathbf{E}_{\text {peak 2 }}(\mathbf{k J} / \mathbf{m o l})$ \\
\hline Friedman & $419.3 \pm 41.1$ & $139.8 \pm 7.0$ \\
ASTM E698 & 390.8 & 135.5 \\
Kissinger & 480.0 & 282.0 \\
\hline
\end{tabular}


M.I. Martín, F.A. López, F.J. Alguacil, M. Romero. Development of crystalline phases in sintered glassceramics from residual E-glass fibres. Ceramics International, 40 (2014) 2769-2776

doi: 10.1016/j.ceramint.2013.10.040

Fig. 4a presents the TTT (Time-Temperature-Transformation) diagrams for the PGF glass after thermal treatment at different temperatures $\left(800-1100^{\circ} \mathrm{C}\right)$ and different times $(2-60 \mathrm{~min})$. The $\mathrm{C}$ shaped curve, which is characteristic of the nucleation and growth processes, shows the combinations of time and temperature needed for the onset of crystallisation. It is observed that the lower temperatures require longer times to initiate crystallisation; thus, the glass begins to devitrify after $60 \mathrm{~min}$ at $850^{\circ} \mathrm{C}$. As the temperature increases, the time required for the onset of crystallisation is reduced; consequently, the glass compacts are highly devitrified after $15 \mathrm{~min}$ at $900^{\circ} \mathrm{C}$. The fastest rates of crystallisation occurred at the highest temperatures studied (1000$1100^{\circ} \mathrm{C}$ ), for which the onset of crystallisation was detected after just 2 min of thermal treatment.

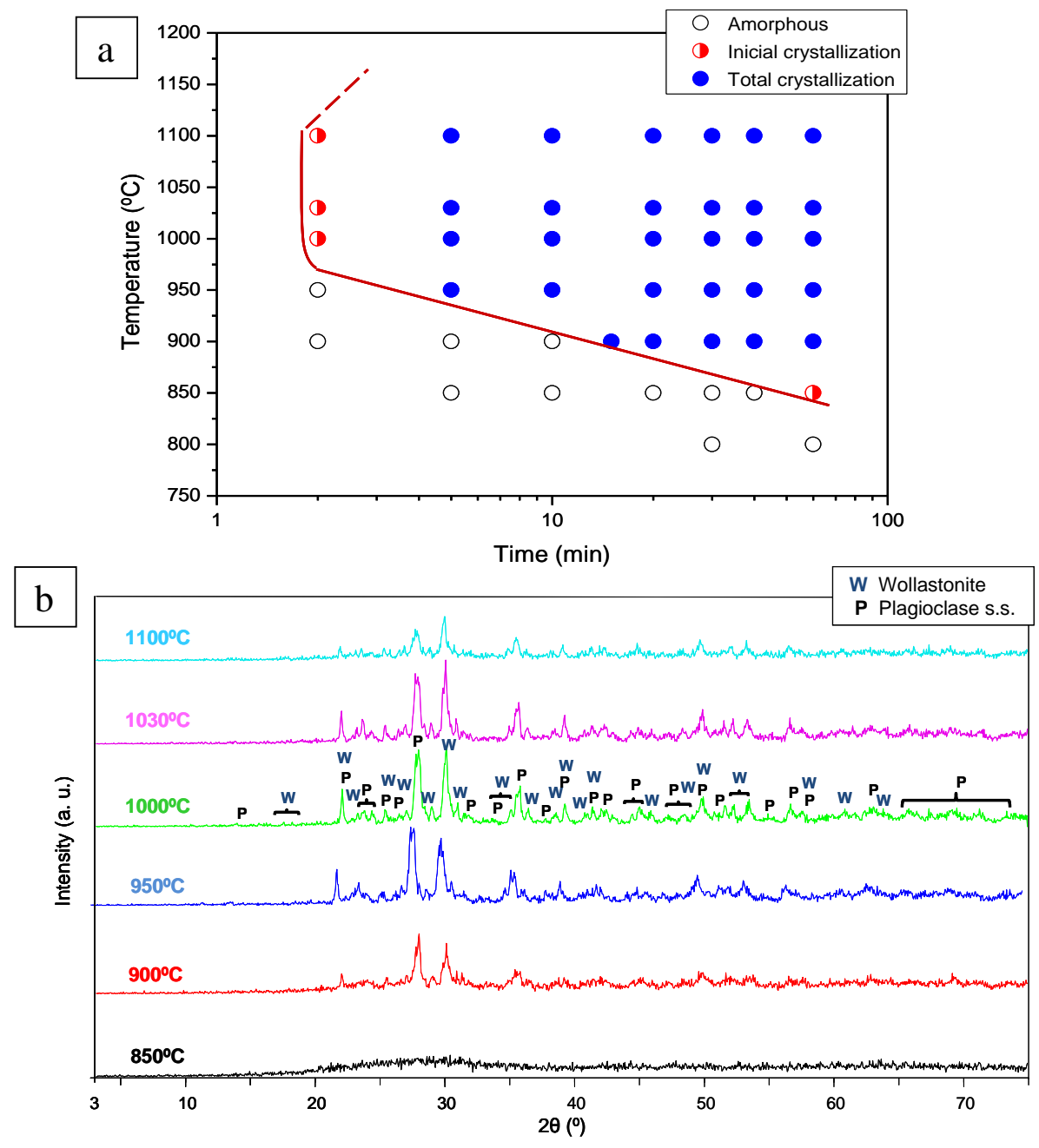

Figure 4. a) TTT curve for the PGF glass; b) X-ray diffractograms of the glass sample after thermal treatment at different temperatures. 
M.I. Martín, F.A. López, F.J. Alguacil, M. Romero. Development of crystalline phases in sintered glassceramics from residual E-glass fibres. Ceramics International, 40 (2014) 2769-2776

doi: 10.1016/j.ceramint.2013.10.040

Fig. 4b shows the X-ray diffractograms for the PGF glass crystallised at different temperatures for $20 \mathrm{~min}$. As shown in the TTT diagrams, glass begins to crystallise at $900^{\circ} \mathrm{C}$. The XRD study conducted on all samples after heat treatment at $\mathrm{T} \geq 900^{\circ} \mathrm{C}$ showed that devitrification of the glass leads to a glass-ceramic material composed of wollastonite $\left(\mathrm{CaSiO}_{3}\right)$ and plagioclase s.s., which corresponds to a series of solid solution between albite $\left(\mathrm{NaAlSi}_{3} \mathrm{O}_{8}\right)$ and anorthite $\left(\mathrm{CaAl}_{2} \mathrm{Si}_{2} \mathrm{O}_{8}\right)$ end-members.

Figure 5 depicts the intensity evolution (obtained from the XRD collected data) of both crystalline phases as a function of temperature and time. The highest intensity diffraction lines, located at 2.98 and $3.19 \AA$ for wollastonite and plagioclase s.s., respectively, have been selected for the representation. Wollastonite and plagioclase crystallise simultaneously through the whole glass devitrification process. Fig. 5 shows that the development of both phases overlaps and that the thermal treatment temperature plays a major role in the relative intensity of both crystalline phases. In the 900 and $950^{\circ} \mathrm{C}$ treatments, the XRD intensity of plagioclase is higher than wollastonite throughout the studied time interval. However, the difference observed between the intensities of both phases is lower at $950^{\circ} \mathrm{C}$, and they become equal after long treatment times $(60 \mathrm{~min})$. As the temperature of the thermal treatment increases, the wollastonite intensity increases while the plagioclase intensity is reduced. As a result, a reversal in the relative intensities of the two phases occurs so that at $1030^{\circ} \mathrm{C}$, treatments longer than 10 min lead to glass-ceramics with wollastonite showing the higher XRD intensity. This behaviour is also observed at $1100^{\circ} \mathrm{C}$ over the whole time interval studied.

Taking into consideration the intensity of both crystalline phases, Fig. 5 shows that the crystallisation degree increases with temperature and reaches a maximum at $1000-1030^{\circ} \mathrm{C}$. Higher temperature results in the partial dissolution of the crystalline phases developed, and the crystallisation degree of the end glass-ceramics is reduced.

Figures 6-9 present FESEM images of the glass-ceramics produced at different temperatures $\left(900-1100^{\circ} \mathrm{C}\right)$ for $20 \mathrm{~min}$. The XRD diffractogram of the material generated after a 20 min thermal treatment at $900^{\circ} \mathrm{C}$ (Figure 4a) reveals that the crystallisation proceeds with the simultaneous precipitation of plagioclase and wollastonite. The FESEM micrographs (Fig. 6) show that, in fact, crystallization begins at the surface of the glass particles, leading to the formation of a crystallization shell surrounding each of the grains. 

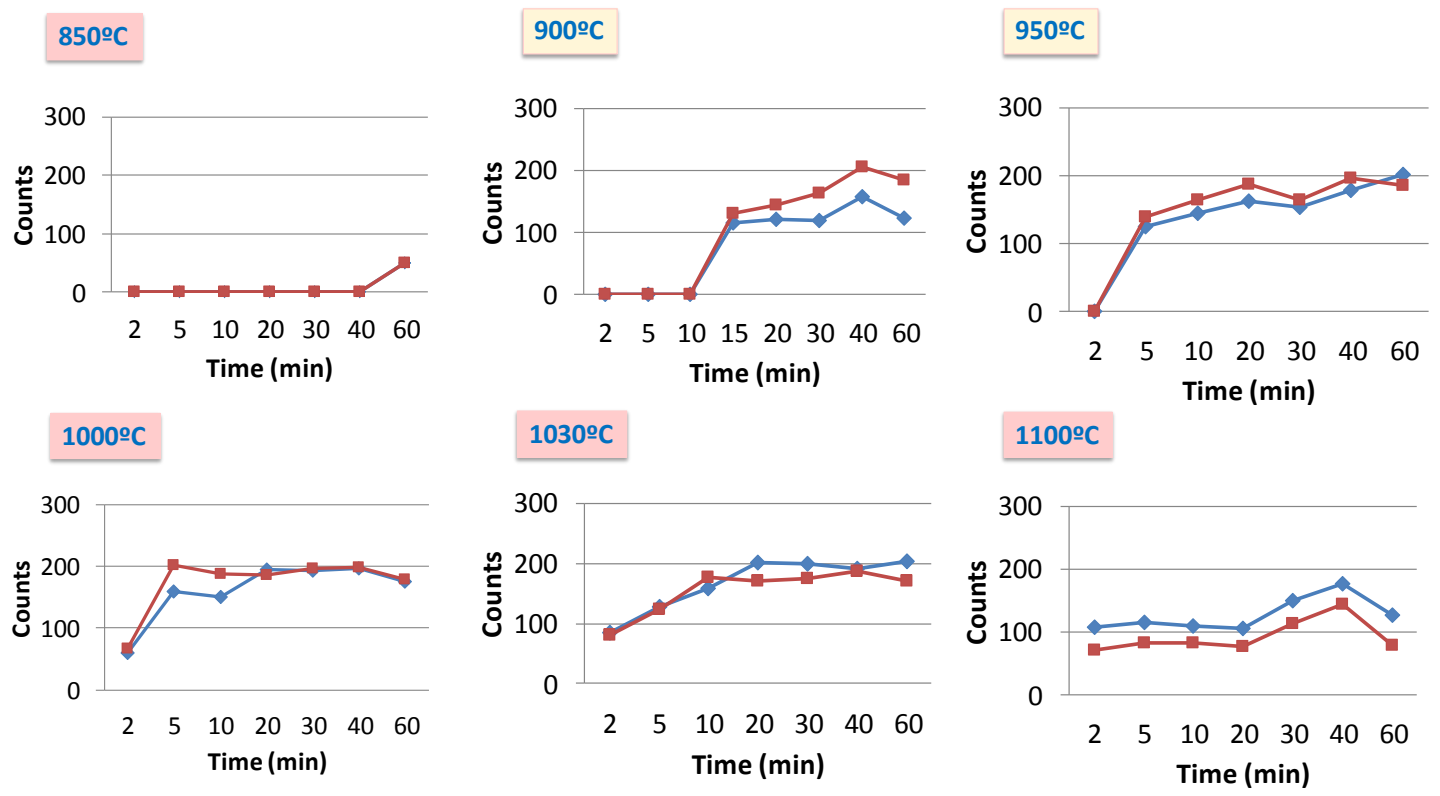

Wollastonite

Plagioclase s.s.

Figure 5. Evolution of the X-ray intensity for wollastonite and plagioclase phases as a function of temperature and time $\left(\mathrm{T}=800-1100^{\circ} \mathrm{C}\right.$ and $\left.\mathrm{t}=2-60 \mathrm{~min}\right)$.
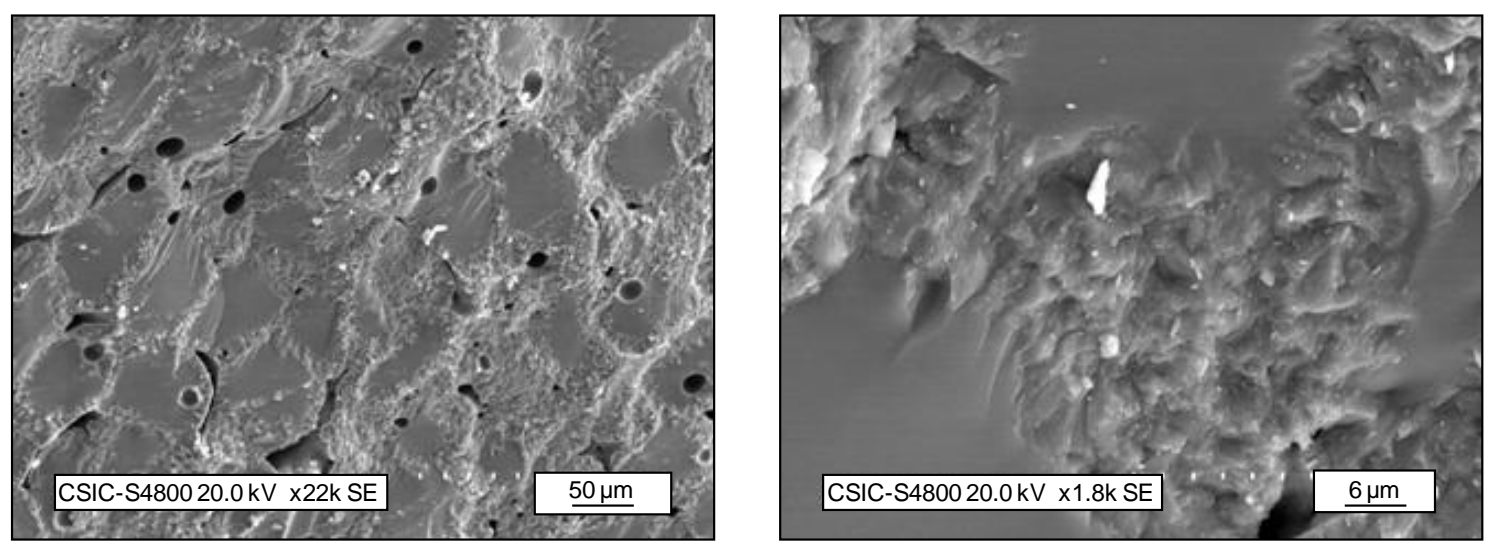

Figure 6. FESEM images of the fresh fractured glass-ceramic obtained at $900^{\circ} \mathrm{C}$ for $20 \mathrm{~min}$.

At low temperature, the formation of liquid phases is depleted and the resulting glass-ceramic material shows a low sintering degree, as denoted by the high volume of open porosity located between the particles. Moreover, certain degree of closed porosity comprised of rounded pores is also evident, which can be probably induced by the crystallization process itself [19]. After the thermal treatment at $950^{\circ} \mathrm{C}$, the glass-ceramic has a high degree of crystallisation, as evidenced by the high density of crystals observed in the FESEM image (Fig. 7). The Si/Ca 
M.I. Martín, F.A. López, F.J. Alguacil, M. Romero. Development of crystalline phases in sintered glassceramics from residual E-glass fibres. Ceramics International, 40 (2014) 2769-2776

doi: 10.1016/j.ceramint.2013.10.040

ratio in the EDS analyses allows differentiation of the wollastonite crystals (W) with a higher calcium content and low $\mathrm{Si} / \mathrm{Ca}$ ratio from the plagioclase crystals $(\mathrm{P})$, which show higher sodium and magnesium contents. The EDS spectra from the wollastonite crystals show the presence of aluminium and indicate the existence of isomorphic substitution of $\mathrm{Si}^{4+}$ by $\mathrm{Al}^{3+}$ cations, which is one of the most typical ionic exchanges in pyroxenes.
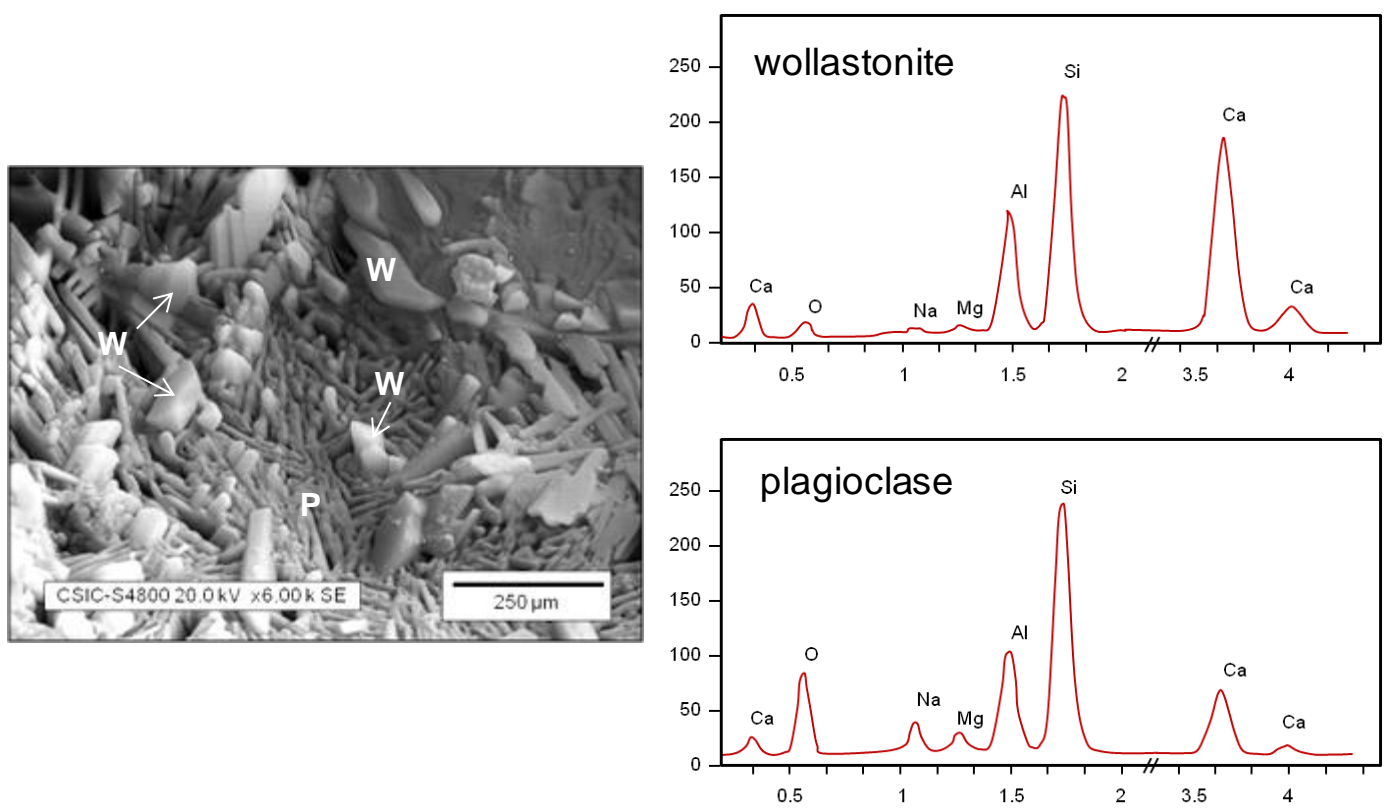

Figure 7. FESEM images of the fresh fractured glass-ceramic obtained at $950^{\circ} \mathrm{C}$ for $20 \mathrm{~min}$ and the EDS spectra of wollastonite (W) and plagioclase (P) crystals.

After the thermal treatment at $1000^{\circ} \mathrm{C}$, the glass-ceramic shows a microstructure composed of a dense network of tightly interlocked wollastonite and plagioclase crystals (Fig. 8a). Both phases exhibit a similar tabular morphology, although plagioclase shows a lower thickness (Fig. 8b). Above $1030^{\circ} \mathrm{C}$, wollastonite becomes predominant over plagioclase and the EDS analyses (Fig. 9) allow the clear distinction of wollastonite crystals with $\mathrm{SiO}_{2} / \mathrm{CaO}$ ratio of $\approx 0.96$, which is close to the theoretical $\mathrm{SiO}_{2} / \mathrm{CaO}$ ratio of $\approx 1.07$ in unsubstituted wollastonite.

For a previous knowledge of technological features of these materials, the glass-ceramic obtained after thermal treatment at $1030^{\circ} \mathrm{C} / 20 \mathrm{~min}$ has been tested in order to determine its water absorption ( $6.9 \times 10-3 \pm 1.6 \times 10-5 \%)$, open porosity (2.2x10-2 $\pm 2.3 \times 10-4 \%)$, bulk density $(2.61 \pm 2.4 \times 10-3 \mathrm{~g} / \mathrm{cm} 3)$ and bending strength $(122 \pm 9 \mathrm{MPa})$ values. With these properties, the developed glass-ceramics are within BIa group (water absorption values lower than $\leq 0.5 \%$, which is characteristic of highly sintered ceramics) of the European Standard EN 1441 [20] and are suitable for floor pavement and wall covering in both indoor and outdoor applications. 

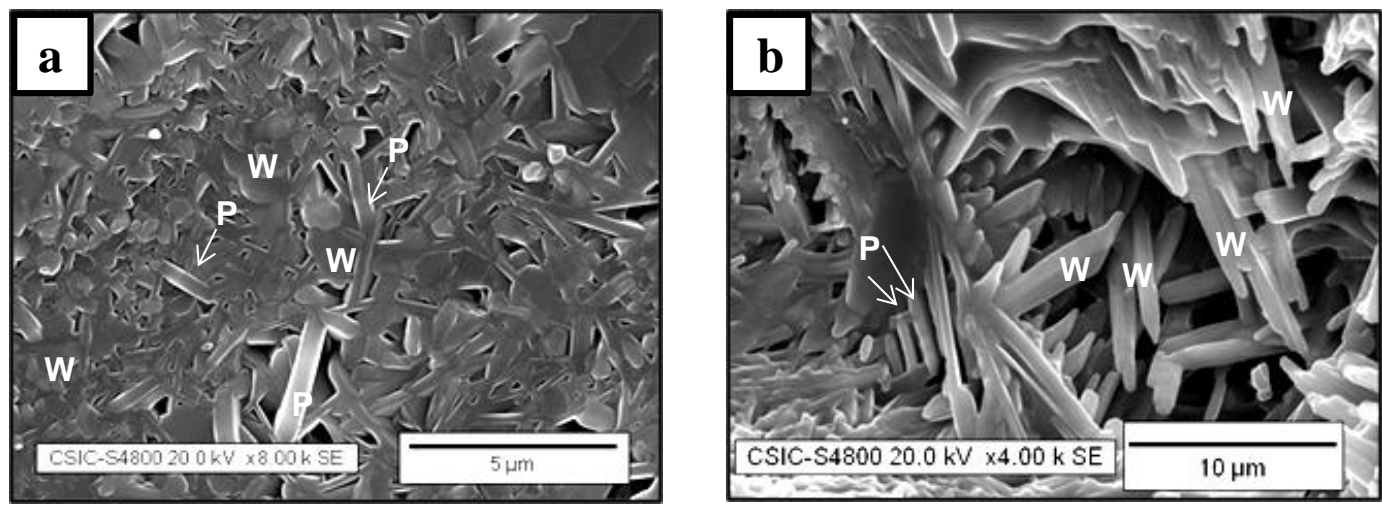

Figure 8. FESEM images of the fresh fractured glass-ceramic obtained at $1000^{\circ} \mathrm{C}$ for $20 \mathrm{~min}$ showing wollastonite (W) and plagioclase (P) crystals.
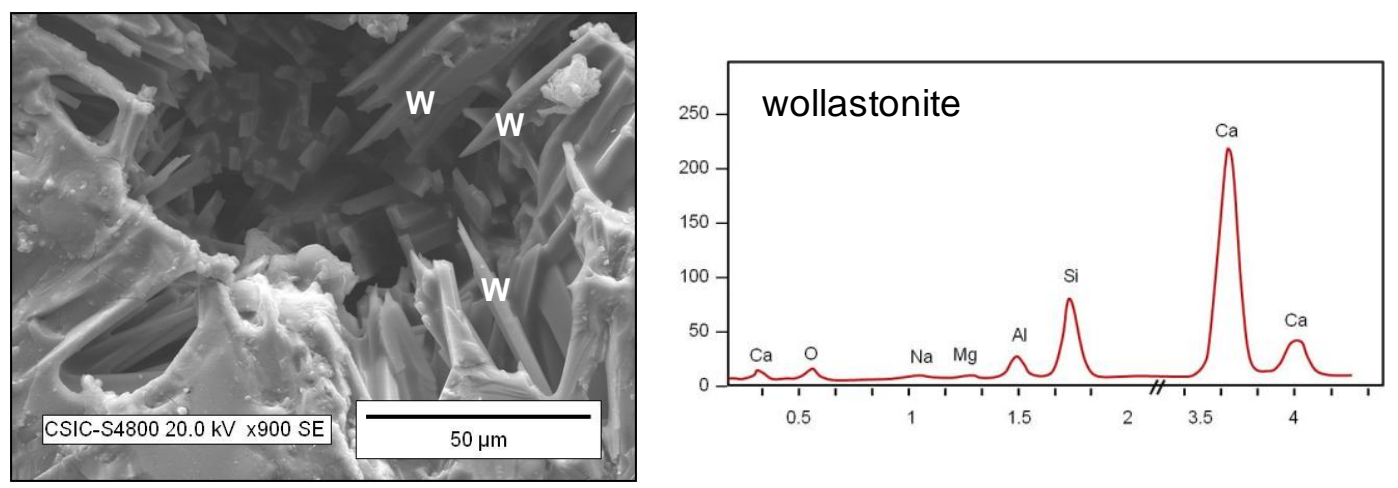

Figure 9. FESEM image of the fresh fractured glass-ceramic obtained at $1100^{\circ} \mathrm{C}$ for $20 \mathrm{~min}$ and the EDS spectrum of wollastonite crystals (W).

\section{Conclusions}

The results of this work demonstrate the feasibility of obtaining wollastonite-plagioclase glassceramics by a sinter-crystallisation process derived from glass fibres recovered by pyrolysis of waste composite materials.

The DSC curve shows two exothermic effects centred at $819-860^{\circ} \mathrm{C}$ and $963-1099^{\circ} \mathrm{C}$, which are associated with the crystallisation of plagioclase s.s. (solid solution between albite $\left(\mathrm{NaAlSi}_{3} \mathrm{O}_{8}\right)$ and anorthite $\left.\left(\mathrm{CaAl}_{2} \mathrm{Si}_{2} \mathrm{O}_{8}\right)\right)$ and wollastonite $\left(\mathrm{CaSiO}_{3}\right)$. The activation energies associated with these crystallisation processes are $390.8-480.0$ and $135.5-282.0 \mathrm{~kJ} / \mathrm{mol}$, respectively. 
M.I. Martín, F.A. López, F.J. Alguacil, M. Romero. Development of crystalline phases in sintered glassceramics from residual E-glass fibres. Ceramics International, 40 (2014) 2769-2776

doi: 10.1016/j.ceramint.2013.10.040

PGF glass begins to crystallise after $60 \mathrm{~min}$ at $850^{\circ} \mathrm{C}$, and the glass compacts are fully devitrified after $15 \mathrm{~min}$ at $900^{\circ} \mathrm{C}$. The fastest rate of crystallisation occurs at $1000^{\circ} \mathrm{C}$, at which point the onset time for crystallisation is only $2 \mathrm{~min}$. Wollastonite and plagioclase crystallise simultaneously through the whole glass devitrification process, and the maximum crystallisation degree takes place at the $1000-1030^{\circ} \mathrm{C}$ temperature interval.

After firing, sintered glass-ceramics from PGF glass show a microstructure composed of a dense network of tightly interlocked wollastonite and plagioclase crystals.

\section{Acknowledgments}

Dr. M. I. Martín thanks the Spanish National Research Council (CSIC), co-financed by the European Social Fund Operational Programme 2007-2013 Adaptability and Employment Multiregional, for the contract JAE-Doc_08-00032. The authors thank IRICA from the University of Castilla-La Mancha (Spain) for experimental assistance with XRD.

\section{References}

[1] J.Ma. Rincon, Principles of nucleation and controlled crystallization of glasses, Polym. Plast. Technol. Eng. 31 (1992) 309-357.

[2] S.R. Teixeira, M. Romero, J.Ma. Rincón, Crystallization of SiO2-CaO-Na2O glass using sugarcane bagasse ash as silica source, J. Amer. Cer. Soc. 93 (2010) 450-455.

[3] W. Hölland, G. Beall, Glass-Ceramic Technology, The American Ceramic Society, Ohio, 2002.

[4] Council Directive 1999/31/EC on the landfill of waste, Official Journal of the European Union L182 (1999) 1-19.

[5] Council Directive 2000/53/EC on end-of life vehicles, Official Journal of the European Union L269 (2000) 34-42.

[6] Council Directive 2002/96/EC of waste electrical and electrical equipment (WEEE), Official Journal of the European Union L37 (2003) 24-38.

[7] A.K. Bledzki, K. Goracy, The use of recycled fibre composites as reinforcement for thermosets, Mech. Compos. Mater. 29(4) (1993) 352-356.

[8] S.J. Pickering, M. Benson, Recovery of materials and energy from thermosetting plastics, Proc. Sixth European Composite Materials Conference, Recycling Concepts and Procedures, European Association for Composite Materials, Bordeaux, France, September 1993, pp. 41-46.

[9] S.J. Evans, P.J., Haines, G.A. Skinner, Pyrolysis-gas-chromatographic study of a series of polyester thermosets, J. Anal. Appl. Pyrolysis 55 (2000) 13-28.

[10] F.A. López, T.A. Centeno, F.J. Alguacil, B. Lobato, Distillation of granulated scrap tires in a pilot plant, J. Hazard. Mater. 190 (2011) 285-292. 
M.I. Martín, F.A. López, F.J. Alguacil, M. Romero. Development of crystalline phases in sintered glassceramics from residual E-glass fibres. Ceramics International, 40 (2014) 2769-2776

doi: 10.1016/j.ceramint.2013.10.040

[11] T. Iwaya, S. Tokuno, M. Sasaki, M. Goto, K. Shibata, Recycling of fiber reinforced plastics using depolymerization by solvothermal reaction with catalyst, J. Mater. Sci. 43 (2008) 24522456.

[12] F.A. López, M.I. Martín, F.J. Alguacil, J. Ma. Rincón, T.A. Centeno, M. Romero, Thermolysis of fiberglass polyester composite and reutilisation of the glass fiber residue to obtain a glass-ceramic material, J. Anal. Appl. Pyrolysis 93 (2012) 104-112.

[13] F.A. López, M.I. Martín, I. García-Díaz, O. Rodríguez, F.J. Alguacil, M. Romero, Recycling of glass fibers from fiberglass polyester waste composite for the manufacture of glass-ceramic materials, J. Environ. Protection 3(8) (2012) 740-747.

[14] International Organization for Standardization (ISO) (1997). ISO 10545-3, Ceramic tiles. Part 3: Determination of water absorption, apparent porosity, apparent relative density and bulk density, Geneva: Switzerland.

[15] European Committee for Standardization (ECS) (2006). EN 843-1, Advanced technical ceramics. Monolithic ceramics. Mechanical properties at room temperature. Part. I: Determination of flexural strength, Brussels: Belgium.

[16] H. Friedman, Kinetics of thermal degradation of char-forming plastics from thermogravimetry, Application to a phenolic plastic, J. Polym. Sci., Part. C 6(1) (1964) 183195.

[17] Arrhenius Kinetic Constants for Thermally Unstable Materials, ASTM International West Conshohochen, PA.

[18] H. Kissinger, Reaction kinetics in differential thermal Analysis, Anal. Chem. 29(11) (1957) 1702-1706.

[19] A. Karamanov, M. Pelino, Induced crystallization porosity and properties of sintered diopside and wollastonite glass-ceramics, J. European Cer. Soc. 28(3) (2008) 555-562.

[20] European Committee for Standardization (ECS) (2003). EN 14411, Ceramic tiles. Definitions, clasifications, characteristics and marking. Brussels: Belgium. 